\title{
ANALYSIS AND EVALUATION OF ADVANTAGES FROM LAPAROSCOPIC APPENDECTOMY
}

\author{
Konstantin Kostov \\ Department of General, Visceral and Emergency Surgery, UMHATEM “N. I. \\ Pirogov" - Sofia, Bulgaria.
}

\section{SUMMARY}

Purpose: The aim of the study is to evaluate the advantages of laparoscopic appendectomy fromour clinical experience in UMHATEM "Pirogov" which resulted in reduced postoperative complications, pain, length of hospital stay, and early return to work.

Material and Methods: Data from a study of a patient group in the Department of General, Visceral and Emergency Surgery of UMBALSM "H. I. Pirogov "for the six-month period (01.01.2019 äî 01.07.2019) were collected.Eighty-one patients with acute appendicitis who underwent laparoscopic appendectomy were selected. Indicators characterizing basic clinical and pathological features (epidemiology, demography, degree of pathological impairment), surgical approach and its outcomes (postoperative complications, postoperative duration), influence of concomitant factors were studied.

Results: The study included 81 patients. The majority of patients were women - 46 (56.79\%), men- 35 $(43.21 \%)$. The mean age of male patients was 31.4 years and for female-28.6 years respectively. Hospitalization times are usually short - most patients are given up to 72 hours $(70-86.42 \%)$. Only eleven patients $(13.58 \%)$ had an extended hospital stay for observation and additional therapy.

Conclusion: Laparoscopic appendectomy was verified as an optimal and safe surgical procedure. Laparoscopic approach reduces post-operative pain, shortens hospital stay, reduces complications, and thereby reducing treatment costs.

Keywords: evaluation, acute appendicitis, laparoscopy, advantages, approach,

\section{INTRODUCTION}

The technology of laparoscopic surgery is rapidly spreading in many areas due to a number of advantages over conventional open surgery [1]. Reducing postoperative pain and shortening hospital stays, as well as earlier return to work, generate a positive socio-economic impact $[2,3]$.

Although this method is minimally invasive, a careful analysis of postoperative complications and causes for conversion was needed $[4,5]$. Open apendectomy (OA) was a gold standard in the treatment of acute appendicitis following the introduction of the Charles McBrney method in 1894 (6). Unfortunately, the identification of acute appendicitis is often a difficult task and is based primarily on clinical signs. The accepted frequency of negative appendectomy for suspected acute appendicitis varies between $15 \%$ and $20 \%$, and for women of childbearing age it is even higher (20-30\%) [7,8].

Laparoscopic appendectomy (LA) evolved from the first one made in 1983 by the German gynecologist KurtSemm [9]. Laparoscopic approach is a method of diagnosing and treating acute appendicitis with its theological advantages over the last three decades. Since then this procedure has been widely used.However, there are still controversies in the literature with regard to the most appropriate way of performing appendectomy in acute appendicitis due to new complications associated with laparoscopy [8,9]. Mini-invasive surgery has proven to be a useful surgical technique. Applying today's technology and skills can now provide a better and cheaper choice of treatment.

Most of the significant advantages of laparoscopic appendectomy are increased cosmetic results and a decrease in the postoperative wound-infections. Some studies show also that laparoscopic appendectomy shortens the hospital stay and recovery period.

Despite the numerous randomized studies comparing laparoscopic and open appendectomy, indications for laparoscopy in patients suspected of acute appendicitis remain controversial, and clinical trials comparing LA with OA have not yet reached consensus on the relative advantages of each procedure [10,11].

This study was designed to evaluate the advantages of laparoscopic appendectomy fromclinical experience in UMHATEM "Pirogov" -reduced postoperative complications, pain, length of hospital stay, and early return to work.

\section{MATERIAL AND METHODS}

For a six-month period (from 1.01.2019 to 1.07.2019) in the General, Visceral and Emergency Surgery section of the UMHATEM "Pirogov" 115 patients with acute appendicitis were operated. In 81 of them a laparoscopic appendectomy was performed. 
Table 1. Mode of surgery

\begin{tabular}{|c|c|}
\hline Mode of surgery & $115(100 \%)$ \\
\hline conventional appendectomy & $34(34.4 \%)$ \\
\hline laparoscopic appendectomy & $81(65.6 \%)$ \\
\hline
\end{tabular}

\section{Laparoscopic technique}

The laparoscopic entry mode was made by a Hasson trocar, placed through the supraumbilical port with open technique. The camera was placed into the abdomen through this trocar and two more trocars were positioned. The first one $(5-\mathrm{mm})$ was placed in the midline just above the pubis and the second one $(10 \mathrm{~mm})$ in the left iliac fossa, in a point on the left-side perfectly symmetrical to the McBurney point.The mesoappendix was clipped and the appendectomy was performed by two endoloops. The operation ends with lavage, drainage through the suprapubic port, and appendix extraction (by endobag).

In this study the parameters - age, sex, clinical signs, treatment and morbidity were followed.

Other traceable parameters were surgical identification, postoperative complications, hospitalization period, and postoperative pain management.

The data from all patients admitted to the hospital with acute appendicitis were carefully systematized, analyzed and summarized.

Patients under 18 years of age are not included in the study.

The results were summarized by monitoring the morbidity up to the one-month post discharge.

\section{RESULTS}

Age distribution shows that the majority of patients were women - 46 (56.79\%), men- 35 (43.21\%).

Table 2. Gender distribution

\begin{tabular}{|c|c|}
\hline gender distribution & $81(100 \%)$ \\
\hline women & $46(56.79 \%)$ \\
\hline men & $35(43.21 \%)$ \\
\hline
\end{tabular}

The mean age of male patients was 31.4 years and for female-28.6 years respectively.

Of the 81 cases of acute appendicitis, seven were misdiagnosed (gynecological diseases - $12.24 \%$ ) but were laparoscopically performed, and one patient was with cecum tumor.

Table 3. Surgical identification

\begin{tabular}{|c|rc|}
\hline Surgical identification & $81 \quad(100 \%)$ \\
\hline Acute appendicitis & $73(90.12 \%)$ \\
\hline gynecological diseases & $7 \quad(8.64 \%)$ \\
\hline Cecum cancer & $1 \quad(1.24 \%)$ \\
\hline
\end{tabular}

Fiveof the cases $(6.17 \%)$ were converted due to complicated intraoperative findings.

About postoperative pain management, it was found that the intensity decreased significantly and almost disappeared at the 30th hour after the intervention.

Complications after surgery were minimized. Hemorrhage localized in the area of one of the working ports was recorded in one patient $(4.08 \%)$ and 5 of the cases $(2.04 \%)$ had data on suppuration of the umbilical port. Intraoperative complications such as haemorrhage, enteral or other organ lesions have not been observed.

Table 4. Postoperative complications

\begin{tabular}{|c|c|}
\hline Postoperative complications & $6(7.41 \%)$ \\
\hline wound infection & $5(6.17 \%)$ \\
\hline wound haemorrhage & $1(1.24 \%)$ \\
\hline
\end{tabular}

Hospitalization periods were usually short - most of the patients (70) were discharged for up to 72 hours $(86.42 \%)$. Only eleven patients had an extended hospital stay for observation and additional therapy (13.58\%).

Table 5. Hospitalization period

\begin{tabular}{|c|c|}
\hline Hospitalization period & $81(100 \%)$ \\
\hline Up to 72 hours hospitalization & $70(86.42 \%)$ \\
\hline Extended hospitalization & $11(13.58 \%)$ \\
\hline
\end{tabular}

There were no deaths in all group-mortality rate was $0 \%$.

\section{DISCUSSION}

Recent studies comparing the clinical outcomes of laparoscopic appendectomy (LA) and conventional appendectomy (OA) [3-5, 7]. Most of them are in favor of a LA $[1,2,3,4,5,7]$. The present study demonstrates the prevalence of female gender and young age in patients with acute appendicitis. These data are consistent with other literature sources $[2,3,5]$. Likewise, the postoperative results correspond to those of the world's scientific communications in this field $[8,10,11,13]$. Patients underwent laparoscopic surgery have been shown to have less duration and intensity of pain, a shorter period of hospitalization, thus reducing the cost of treatment. This is comparable to world literature.

The wound infections were 3 times higher in the open appendectomy group, with only 5 cases $(6.17 \%)$ of port site infection in the laparoscopic appendectomy group. One of the reasons for the lower incidence of port site infections in the laparoscopic appendectomy group was that the inflamed appendix was removed through the operating port without making contact with the wound and endobag extraction was used. This is was significant finding in our laparoscopic appendectomy analysis $[11,12]$. 
The incidence of histologically normal appendix in patients with clinical signs and symptoms of acute appendicitis ranges from 8 to $41 \%$ [14]. For this reason we contend that the laparoscopic procedure is the better approach in cases of suspected acute appendicitis-all in young females and obese patients, but also in children and the elderly. Laparoscopy allowedaccurate diagnosis and occured management of other differential benign and malignant pathologies. In our experience we have found endometriosis, pelvic inflammatory disease, adnexal torsion, Crohn's disease, solitary cecal diverticulitis, omental infarction, Meckel's diverticulitis, and cecal neoplasm [12, 13].

Shorter length of hospital stay is a wellknown advantage of minimally invasive surgery, and in this study, no hospital stay length advantage was associated with uncomplicated appendicitis. With laparoscopic appendectomy technique, early discharge within the first 24-48 hours after appendectomy for uncomplicated appendici- tis does not seem to lead to a significant increase in the rate of postoperative complications when compared to the results of other world studies [13, 14].

The levels of surgical complications are minimized. The incidence of intra- and postoperative haemorrhage was negligible $(<5 \%)$. Suppuration levels of operating ports also $<6.2 \%$. These results would have been even more contrasting and expressive if we presented a comparative group of conventional appendectomy in details, which was a limiting factor in this study $[12,13,14]$.

\section{CONCLUSION}

Laparoscopic appendectomy was verified as an optimal and safe surgical procedure. It may be a diagnostic and therapeutic approach to missed gynecological diseases at initial examination. Laparoscopic surgery reduces postoperative pain, shortens hospital stay, reduces complication levels, thereby reducing and treatment costs.

\section{REFERENCES:}

1. Costa-Navarro D, JiménezFuertes M, IllànRiquelme A. Laparoscoic appendectomy: quality care and cost-effectiveness for today's economy. World J Emerg Surg. 2013 Nov $1 ; 8(1)$ : 45. [PubMed]

2. Editorial. A sound approach to the diagnosis of acute appendicitis. Lancet. 1987 Jan 24; 1(8526):198-200. [PubMed]

3. Horvath P, Lange J, Bachmann R, Struller F, Königsrainer A, Zdichavsky M. Comparison of clinical outcomes of laparoscopic versus open appendectomy for complicated appendicitis. Surg Endosc. 2017 Jan;31(1):199-205 [PubMed]

4. Kehagias I, Karamanaks SN, Panagiotopoulos S, Panagopoulos K, Kalfarentzos F. Laparoscopic versus open appendectomy: which way to go? World J. Gastroenterol. 2008 Aug 21; 14(31):4909-14. [PubMed]

5. Wullstein C, Barkhausen S, Gross E. Results of laparoscopic versus conventional appendectomy in complicated appendicitis. Dis Colon Rectum. 2001 Nov;44(11):1700-5. [PubMed]

6. McBurney C. IV. The incision made in the abdominal wall in cases of appendicitis, with a description of a new method of operating. Ann Surg. 1894 Jul;20(1):38-43. [PubMed]

7. Van LV, Jose MV. Laparoscopic Versus Conventional Appendectomy. Ann Surg. 1993 Nov; 218(5):685-692. [PubMed]

8. Nana AM, Ouandji CN, Simoens C, Smets D, Mendes da Costa P. Laparoscopic appendectomies: results of a monocentric prospective and nonrandomized study. Hepatogastroenterology. 2007 Jun; 54(76):1146-1152. [PubMed]

9. Semm K. Endoscopic appendectomy. Endoscopy. 1983 Mar;15(2):5964. [PubMed]

10. Long KH, Bannon MP, Zietlow SP, Helgeson ER, Harmsen WS, Smith $\mathrm{CD}$, et al. A prospective randomized comparison of laparoscopic appendec- tomy with open appendectomy: clinical and economic analyses. Surgery. 2001 Apr;129(4):390-400. [PubMed]

11. Del Pino C, Muñoz R, Rada G. Laparoscopic versus open appendectomy for complicated appendicitis. Medwave. 2018 Dec 11;18(8):e7370. [PubMed]

12. Talha A, El-Haddad H, Ghazal AE, Shehata G. Laparoscopic versus open appendectomy for perforated appendicitis in adults: randomized clinical trial. Surg Endosc. 2020 Feb; 34(2):907-914. [PubMed]

13. Delibegoviæ S, Karabeg R, Simatoviæ M. Securing the base of the appendix during laparoscopic appendectomy. Med Glas (Zenica). 2020 Aug 1;17(2):252-255. [PubMed]

14. Siotos C, Stergios K, Prasath V, Seal SM, Duncan MD, Sakran JV, Habibi M. Irrigation Versus Suction in Laparoscopic Appendectomy for Complicated Appendicitis: A Meta-analysis. J Surg Res. 2019 Mar;235:237243. [PubMed]

Please cite this article as: Kostov K. Analysis and evaluation of advantages from laparoscopic appendectomy. $J$ of IMAB. 2022 Jan-Mar;28(1):4183-4185. DOI: https://doi.org/10.5272/jimab.2022281.4183

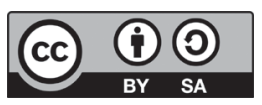

\author{
Address for correspondence: \\ Konstantin Kostov, MD, PhD \\ Surgical Clinic, UMHATEM "N. I. Pirogov" \\ 21, Totleben Blvd., 1606 Sofia, Bulgaria. \\ E-mail: dr.k.kostov@gmail.com
}

